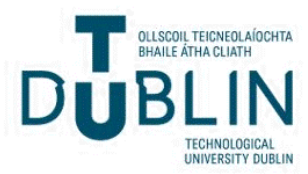

Technological University Dublin

ARROW@TU Dublin

\section{The Development and Trial of Systematic Visual Search: a visual inspection method designed to improve current workplace risk assessment practice}

Victor Hrymak

Technological University Dublin, victor.hrymak@tudublin.ie

Jan DeVries

National Technological University, Jan.Devries@TUDublin.ie

Follow this and additional works at: https://arrow.tudublin.ie/schfsehrep

Part of the Environmental Public Health Commons

\section{Recommended Citation}

Hrymak, V. \& DeVries, J. (2020). The Development and Trial of Systematic Visual Search: a visual inspection method designed to improve current workplace risk assessment practice. Policy and Practice in Health and Safety, vol. 18, no. 1, doi:10.1080/14773996.2019.1708615

This Article is brought to you for free and open access by the School of Food Science and Environmental Health at ARROW@TU Dublin. It has been accepted for inclusion in Reports by an authorized administrator of ARROW@TU Dublin. For more information, please contact arrow.admin@tudublin.ie, aisling.coyne@tudublin.ie, gerard.connolly@tudublin.ie.

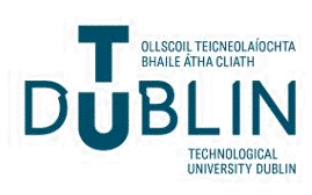




\section{The development and trial of systematic visual search: a visual inspection method designed to improve current workplace risk assessment practice}

\section{Victor Hrymak \& Jan M. A. de Vries}

To cite this article: Victor Hrymak \& Jan M. A. de Vries (2020): The development and trial of systematic visual search: a visual inspection method designed to improve current workplace risk assessment practice, Policy and Practice in Health and Safety, DOI: 10.1080/14773996.2019.1708615

To link to this article: https://doi.org/10.1080/14773996.2019.1708615

曲 Published online: 06 Jan 2020.

Submit your article to this journal $\widetilde{ }$

View related articles $\asymp$

View Crossmark data $\nearrow$ 


\title{
The development and trial of systematic visual search: a visual inspection method designed to improve current workplace risk assessment practice
}

\author{
Victor Hrymak ${ }^{a}$ and Jan M. A. de Vries ${ }^{b}$

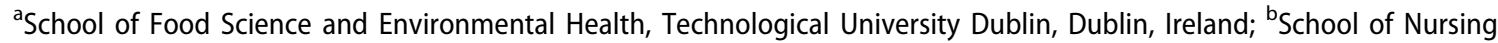 \\ \& Midwifery, The University of Dublin, Trinity College, Dublin, Ireland
}

\begin{abstract}
Visual inspection is a core element in hazard identification. However, poorly conducted visual inspections are problematical for workplace inspection practice as observable hazards that should be seen, are often missed. To address this problem, a novel method; systematic visual search, was developed and tested under randomised controlled trial conditions using commercial kitchens as workplaces. A total of 211 participants were recruited and in the control condition, $N=104$ conducted their visual inspection as normal. In the experimental condition, $N=107$ received training in the use of systematic visual search. Control group participants were only able to identify a circa mean $33 \%$ of observable hazards in the kitchens. In contrast experimental group participants, using systematic visual search, observed a circa mean $50 \%$ of observable hazards present. This $17 \%$ improvement was highly significant, with a large effect size ( $p \leq .001$, Cohen's $d=1.85$ ).
\end{abstract}

ARTICLE HISTORY

Received 11 July 2019

Accepted 20 December 2019

\section{KEYWORDS}

Workplace; visual inspection; risk assessment; safety auditing

\section{Introduction}

Workplace inspections conducted for risk assessment or safety auditing purposes will involve two basic methods; hazard identification and risk evaluation. An extensive listing of these methods is given by; Gould, Glossop, and Ioannides (2005); ISO 31010 (2009); Marhavilas, Koulouriotis, and Gemeni (2011); Mariken, Everdij, and Blom (2013). Typically, environmental health and safety (EHS) related inspections are conducted by professionals who will attend the workplace under analysis and begin the hazard identification phase by looking for, asking questions about, reading relevant documents and using scenario analysis by thinking about existing or potential workplace hazards (Clift, Lawton, \& Maguire, 2011; Hrymak, DeVries, \& Leva, 2015; Neathey et al., 2006; Woodcock, 2014). This results in a listing of in situ workplace hazards which together with risk evaluation, subsequently becomes a risk assessment.

Thus hazard identification is crucial, as Aven (2011, p. 62) points out; a hazard that is not identified cannot be dealt with. However as scholars have repeatedly shown, when EHS professionals conduct workplace safety inspections, there are no uniform approaches (Clift et al., 2011; Hrymak et al., 2015; Lenhardt \& Beck, 2016; Neathey et al., 2006). Furthermore, a fundamental requirement for any workplace inspection task, that of the visual search process to actually observe hazards in situ, has not been subject to empirical research or any attempted standardisation by EHS professional bodies. Visual inspection performance by EHS professionals remains of fundamental importance as Wade and Swanston (2013) state; we humans derive most understanding of our surroundings, from our visual sense. This can be mentally 
envisaged using scenario analysis and considering the accuracy of workplace risk assessments conducted by EHS professionals, who are blindfold!.

In addition the current lack of research on workplace visual inspection accuracy may be providing a false sense of security for the EHS profession, if the fundamental visual search behaviour lacks precision. As Woodcock (2014) describes, the hazard identification process arising from the inspection currently seems to consist of done or not done, with little consideration for accuracy. To further illustrate the possible consequences of this issue, the following three examples demonstrate the effect that visual inspection failures have had in terms of workplace fatalities and economic loss.

Hopkins (2011) reported how four senior managers, conducted an informal safety related audit termed a 'management visibility tour' of the Gulf of Mexico Deepwater Horizon oil rig, a few hours before the explosion in 2011. These managers did not look at any process related indicators that almost certainly would have indicated, and thereby prevented, the impending explosion.

Lockhart (2011) wrote the coroner's report into the fatalities of fourteen elderly residents from a fire at the Rosepark Nursing Home in Scotland. Reporting under judicial review conditions, he concluded that; had the health and safety consultant who recently inspected the premises observed the flammable aerosol cans inappropriately stored in an electrical cabinet, the fatalities would have been prevented.

The US Governmental Audit Office (2004) reported that in at least two cases of fatalities from nursing home fires in the US, the fire surveyors who conducted prior inspections failed to identify breaches (openings or holes) in fire compartments (walls floors and ceilings). The Audit Office stated that these observable hazards directly contributed to subsequent deaths. In each of these three examples, the lack of accuracy in the basic visual inspection conducted was the problem; observable hazards were simply not seen.

Where applied empirical research has been conducted on visual search performance, it has centred on specific sectors including industrial quality control, aviation maintenance, construction engineering, security screening and medical imaging (in sectoral order: Albert, Hallowell, \& Kleiner, 2014; Biggs \& Mitroff 2014; Carter \& Smith, 2006; Drury \& Watson, 2002; Gallwey, 1998; Hollis \& Bright, 1999; Melloy, Harris, \& Gramopadhye, 2000; Mitroff \& Biggs, 2014; Moore et al., 2001; Perlman, Sacks, \& Barak, 2014; Pinto, Ribeiro, \& Nunes, 2013; Rao, Bowling, Khasawneh, Gramopadhye, \& Melloy, 2006; Wolfe, Evans, Drew, Aizenman, \& Josephs, 2015; Wolfe, Horowitz, \& Kenner, 2005). All these studies critically demonstrate human cognitive failings and intrinsic inspection difficulties. Biggs and Mitroff (2014) succinctly encapsulates this situation by describing visual inspection as an error prone task that is difficult to do well. There are many sensory perceptual, cognitive bias and organisational reasons for visual inspection failures and these are summarised in Table 1.

\subsection{The lack of guidance and standardisation for visual inspection conduct}

Visual inspection is intrinsically expected as part of any workplace risk assessment. This hazard identification method is routinely advocated by professional bodies and regulators including the British, Irish and US labour inspectorates. However, there is scant methodological guidance for EHS professionals on exactly how to conduct visual inspections in a competent manner. For example, The UK Labour inspectorate vaguely states that 'a good starting point for a risk assessment is to walk around your workplace and think about any hazards' (HSE, 2014). The Irish Labour Inspectorate states that risk assessors should 'walk around the workplace and look afresh at what could reasonably be expected to cause serious harm' (HSA, 2006). Similarly, the US Labour Inspectorate states that inspectors will 'walk through the workplace inspecting for hazards that could lead to employee injury or illness' (OSHA, 2016).

In an exploratory study of Irish workplace inspection conduct, Hrymak et al. (2015) interviewed forty experienced EHS professionals. These authors found that during workplace inspections, there was an overarching methodological paradigm of look, ask and read used for the hazard identification phase. 
Table 1. Causes of visual inspection error; a summary listing.

\begin{tabular}{|c|c|c|}
\hline Cause & Brief explanation & Reference \\
\hline Limitations in memory & $\begin{array}{l}\text { Holding data in visual search memory reduces the rate } \\
\text { of evaluation of new targets }\end{array}$ & Drew, Boettcher, and Wolfe (2015) \\
\hline $\begin{array}{l}\text { Interference between } \\
\text { memory sets }\end{array}$ & $\begin{array}{l}\text { Missing that an M6 sized bolt is incorrectly stored in an } \\
\text { M8 container }\end{array}$ & Baddeley (2007) \\
\hline Capacity of memory & Too many objects to memorise correctly & Baddeley (2007) \\
\hline Memory degredation & A decay in the amount of memory from age or disease & Baddeley (2007) \\
\hline Subsequent search misses & $\begin{array}{l}\text { The observation of a target negatively affects the } \\
\text { observation of subsequent targets }\end{array}$ & $\begin{array}{l}\text { Clark, Cain, Adcock, and Mitroff (2014); } \\
\text { Fleck, Samei, and Mitroff (2010); } \\
\text { Mitroff, Biggs, and Cain (2015). }\end{array}$ \\
\hline Target prevalence & $\begin{array}{l}\text { Lower visual inspection performance is related to very } \\
\text { low levels of target prevalence }\end{array}$ & Mitroff and Biggs (2014) \\
\hline Speed accuracy trade off & $\begin{array}{l}\text { The speed of search and observational accuracy are } \\
\text { inversely related }\end{array}$ & $\begin{array}{l}\text { Biggs and Mitroff (2014); Melloy et al. } \\
\text { (2000); Hollis and Bright (1999) }\end{array}$ \\
\hline Vigilance and diligence & $\begin{array}{l}\text { How well the observational task is conducted, affects } \\
\text { visual inspection performance }\end{array}$ & $\begin{array}{l}\text { Drury and Watson (2002); } \\
\text { Gallwey (1998) }\end{array}$ \\
\hline In-attentional blindness & $\begin{array}{l}\text { When a given attentional set is adopted, an } \\
\text { unexpected object may go undetected if it does not } \\
\text { share the same set properties }\end{array}$ & $\begin{array}{l}\text { Aimola-Davies, Waterman, White, and } \\
\text { Davies (2013); Drew, Vo, and } \\
\text { Wolfe (2013) }\end{array}$ \\
\hline $\begin{array}{l}\text { Hybrid foraging } \\
\text { search behaviour }\end{array}$ & $\begin{array}{l}\text { Visual inspection performance is influenced by previous } \\
\text { mean times taken to observe targets }\end{array}$ & $\begin{array}{l}\text { Cain, Adamo, and Mitroff (2013); } \\
\text { Wolfe, Aizenman, Boettcher, and } \\
\text { Cain (2016) }\end{array}$ \\
\hline Expert judgement & Professional judgement accuracy varies & $\begin{array}{l}\text { Aronson (2012); } \\
\text { Gilovich et al. (2013); } \\
\text { Kahneman (2011) }\end{array}$ \\
\hline Confirmation bias & A tendency to see what you expect to see & $\begin{array}{l}\text { Gilovich et al. (2013); } \\
\text { Kahneman (2011) }\end{array}$ \\
\hline Outcome bias & A tendency to ignore warnings & $\begin{array}{l}\text { Gilovich et al. (2013); } \\
\text { Kahneman (2011) }\end{array}$ \\
\hline Ambiguity in definitions & $\begin{array}{l}\text { A lack of precision in defining a hazard allowing that } \\
\text { object to be mis-interpreted as not of interest }\end{array}$ & $\begin{array}{l}\text { Aven (2011); } \\
\text { Johansen and Rausand (2015) }\end{array}$ \\
\hline $\begin{array}{l}\text { The lack of guidance in visual } \\
\text { inspection conduct }\end{array}$ & $\begin{array}{l}\text { Idiosyncratic behaviour resulting in some objects of } \\
\text { interest not being observed due to visual } \\
\text { inspection conduct }\end{array}$ & Drury and Watson (2002) \\
\hline $\begin{array}{l}\text { Degrading resolution away } \\
\text { from the fovea }\end{array}$ & $\begin{array}{l}\text { Objects in peripheral vision are more difficult to } \\
\text { clearly observe }\end{array}$ & Eckstein (2011) \\
\hline $\begin{array}{l}\text { Variability in the visual } \\
\text { environment }\end{array}$ & $\begin{array}{l}\text { The complexity of the visual search environment affects } \\
\text { performance }\end{array}$ & Eckstein (2011) \\
\hline
\end{tabular}

However, in terms of visual inspection behaviour, there was little consensus as to what extent premises should be looked at, in what order to look, in what detail or for how long. One of the findings of this study was that this variation in visual inspection behaviour, must be contributing to observable in situ workplace hazards being missed by some EHS professionals.

Efforts to standardise EHS inspections have generally focussed on formalising the recording of hazards through the use of checklists and templates (Clift et al., 2011; Neathey et al., 2006). Whilst this certainly helps the inspector and favours the reporting of hazards in a standardised way, it may not improve the visual inspection performance itself. This epitomises the situation, practice in this field is largely ideosyncratic rather than informed by research evidence.

An illustrative example is given by Hollis and Bright (1999) in their study of ten surveyors who conducted visual inspections. Each surveyor was tasked with producing a condition report for the same dwelling which was intended for use by prospective house purchasers. The dwelling under analysis had six known housing defects already identified by the Hollis and Bright (1999) research team. These defects were all significant, and would be expected to have been observed by competent professionals. The results were as follows; one surveyor observed all six defects, one surveyor did not observe any defects and five surveyors observed two defects only. Time spent on site was given as the reason for the discrepancy, with the more visual inspection time used, the better the results. 


\subsection{Cognitive bias}

It is important to highlight that it is in the human condition, to be flawed in our perceptive abilities including our intuitive expertise (Kahneman, 2011). This author goes on to present evidence for how experts can be misled in their eventual conclusions by existing cognitive processes such as confirmation and outcome bias. Confirmation bias can lead to professionals 'seeing' what they expect to see. Outcome bias can happen when abnormal conditions occur frequently, and are normalised and subsequently ignored. Aronson (2012) commenting on cognitive bias, highlights that expectations and biases play a dominant role in our perception and that confidence in one's judgement is not necessarily related to the reliability of that judgment. Gilovich, Griffin, and Kahneman (2013) summarises this human characteristic by stating that 'experts are mostly right, but due to cognitive limitations get it wrong as well'. Montibeller and von Winterfeldt (2015) express their surprise that research into cognitive and motivational bias, as applied to the field of risk analysis, has not yet been conducted.

\subsection{Systematic visual search}

In attempting to improve the situation, examples from other sectors using visual inspection were investigated together with recommendations from the visual search literature. The UK based Royal Institute of Chartered Surveyors, has long standardised visual inspection conduct amongst its practitioners (Hollis, 2000; RICS, 2002, 2010). This professional body recommends observing any room or area using the following consistent and iterative order here summarised as; ceiling first, then individual walls, then the floor. Similarly, specific and very detailed procedures for visual inspection in the aviation industry have become the norm (Drury \& Watson, 2002). Furthermore the literature presents evidence that using a set eye scanning pattern for the visual search itself, may bring advantages in terms of more hazards observed when compared to random visual search behaviour (Nalangula, Greenstein, \& Gramopadhye, 2006; Nickles, Melloy, \& Gramopadhye, 2003; Wang, Lin, \& Drury, 1997).

The novel method developed for this study has been based on these proceduralised examples and literature recommendations. Hence systematic visual search requires a rigorous step by step approach to the selection of the object to be observed, followed by the use of a set eye scanning pattern. Clarity of instruction and procedure were instilled by providing participants with a highly systematic and strict protocol for the visual inspection itself. This proceduralisation was intended to minimise sensory perceptual, cognitive bias and organisational factors from affecting the observation of workplace hazards. This paper provides an account of a series of randomised controlled trials in which systematic visual search was compared with how EHS professionals commonly conduct their workplace visual inspections.

\section{Methodology}

\subsection{Participants}

After ethical approval for this study was granted by Technological University Dublin (TU Dublin), a total of 211 participants took part in this study. Of this total $N=102$ participants were full time students who were studying on food safety and occupational safety related degree level programmes provided by TU Dublin. All of these full time students had completed at least one year of practical food safety and occupational safety experience. In addition there were $N=71$ participants who worked in food safety related employment and were studying part time for food safety and occupational safety related programmes in TU Dublin. Finally there were $N=38$ professionals all working full time in food safety related employment. In short, all the participants recruited had visual inspection experience in assessing workplaces for compliance with food safety and occupational safety legislation. 
Table 2. Demographic comparison of intervention and control group participants.

\begin{tabular}{|c|c|c|c|}
\hline & Control group & Experimental group & Total \\
\hline$N$ & 107 & 104 & 211 \\
\hline$N$ Males & 44 & 49 & 93 \\
\hline$N$ Females & 63 & 55 & 118 \\
\hline$N$ Full time students & 51 & 51 & 102 \\
\hline$N$ Part time students & 37 & 34 & 71 \\
\hline Mean years of experience of part time students & $\begin{array}{c}\text { Mean }=4.26 \\
S D=3.02\end{array}$ & $\begin{array}{c}\text { Mean }=7.39 \\
S D=5.74\end{array}$ & \\
\hline$N$ full time professionals & 19 & 19 & 38 \\
\hline Mean years of experience of full time professionals & $\begin{array}{c}\text { Mean }=16.47 \\
S D=10.30\end{array}$ & $\begin{array}{c}\text { Mean }=13.79 \\
S D=10.50\end{array}$ & \\
\hline
\end{tabular}

After random assignment creating control and experimental groups, the descriptive demographics emerged as follows (see Table 2). This table demonstrates that the two treatment groups were suitable for comparison.

\subsection{Design and procedure}

This study made use of a randomised controlled trial experimental design and in total twelve trials were conducted. In each trial, participants were randomly assigned to either a control condition or experimental condition. In the control condition, participants received a general recap on food and safety hazards in kitchens as well as instructions to use their customary way of visual inspection. This was immediately followed by visual inspections of an industry standard kitchen located within the TU Dublin campus. In the experimental condition, participants also received the same general recap but this was followed by training in the systematic visual search method. This experimental group were then instructed to perform a visual inspection of the same kitchen as the control group, but directed to use systematic visual search.

Control and experimental groups accessed the kitchens at different times, so were never in contact with each other during the study. Sheets of paper where participants wrote down the hazards they had observed, were collected after the inspection by the researchers. The findings were compiled and comparisons were made between the two groups in regard to the number and characteristics of hazards observed.

\subsection{Descriptions of the kitchens used}

A total of five fully functioning industry standard kitchens were used. All the kitchens were located within the TU Dublin campus. These kitchens are used for the education and training of food professionals and are constructed to provide high quality, fine dining cuisine. The five kitchens used had a mean floor area of $95 \mathrm{~m}^{2}$ and varied in size from $73-117 \mathrm{~m}^{2}$. Figure 1 illustrates the type of kitchen used in this study and the photograph depicts kitchen 1.

Table 3 summarises the range of hazards present within the kitchens used, together with additional descriptive characteristics.

Examples of planted hazards are shown in Figures 2-5.

\subsection{Ascertaining the number of kitchen hazards prior to inspections}

There were two methods used by the researchers to ascertain a listing of the hazards in the relevant kitchens. The first was by using systematic visual search to conduct an actual inspection prior to participant involvement. The second method was to plant deliberately manipulated hazards in pre-set locations. For example in each trial; water bottles were relabelled with toxic or flammable pictograms, packets of cigarettes were left on shelves, food packages such as bags of flour or rice were left on the floor and mouse traps were left under equipment. These plants were kept as similar as possible in terms of number and 


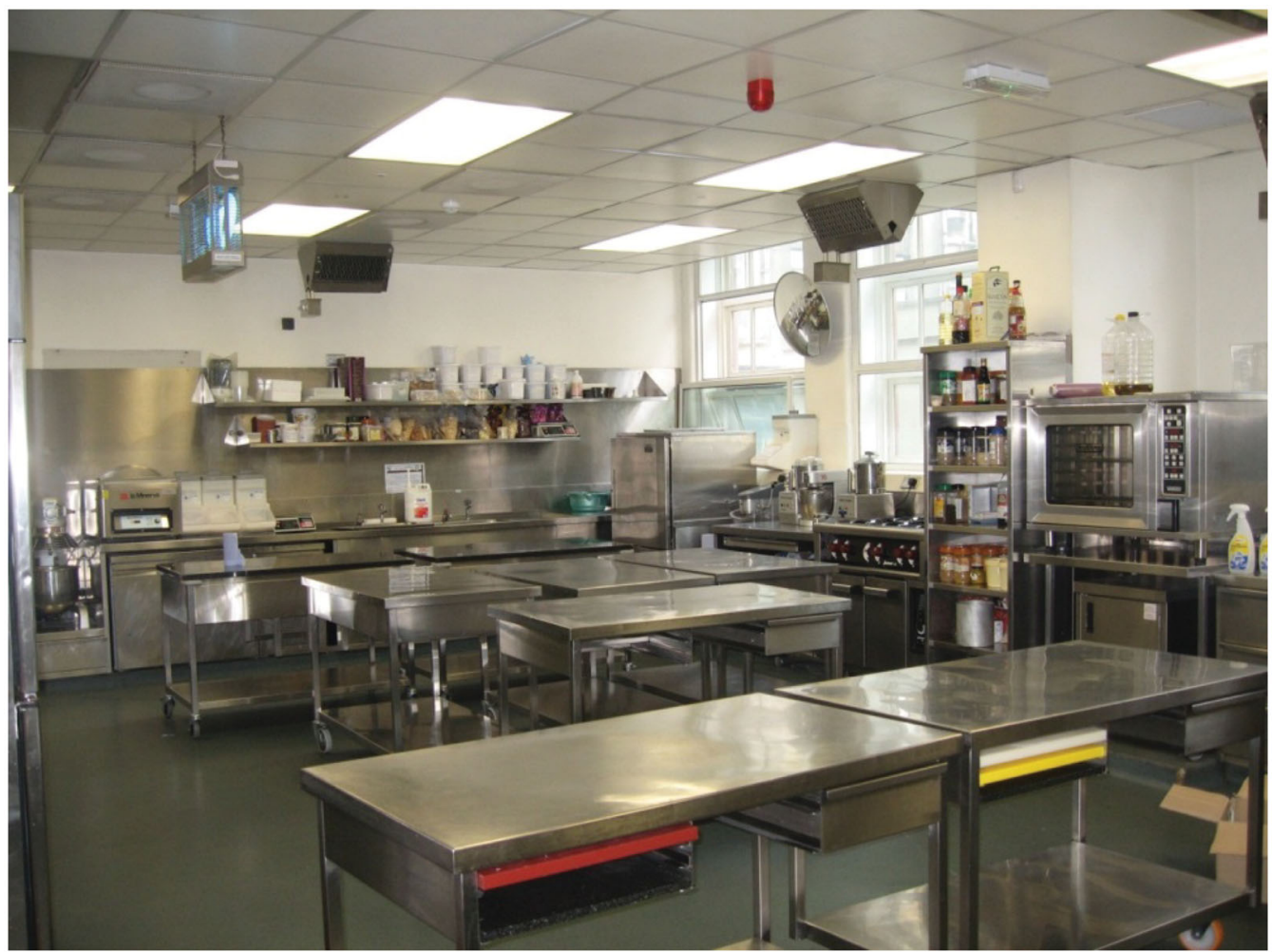

Figure 1. An example of one of the kitchens used in the study.

Table 3. Description of the hazards within kitchens.

\begin{tabular}{|c|c|c|c|c|c|}
\hline Hazard & Location & $\begin{array}{c}\text { Risk } \\
\text { category }\end{array}$ & Risk rating & Field of view & Provenance \\
\hline Covered or interfered with smoke detector & Ceiling & Occupational & High & Open* & Planted \\
\hline all surfaces not readily cleansable & Walls & Food & Medium & Obscured** & Existing \\
\hline Shelf surfaces not readily cleansable & Shelves & Food & Medium & Open & Existing \\
\hline Mouse traps under equipment & Floor & Food & High & Obscured & Planted \\
\hline Ceiling tiles removed & Ceiling & Food & Medium & Open & Planted \\
\hline Ceiling tiles in disrepair & Ceiling & Food & Medium & Open & Existing \\
\hline$N=10$ tea candles & Shelves & Occupational & Medium & Open & Planted \\
\hline Flammable liquid in a $500 \mathrm{ml}$ bottle & Shelves & Occupational & Medium & Open & Planted \\
\hline Flammable $250 \mathrm{ml}$ aerosol can & Shelves & Occupational & Medium & Open & Planted \\
\hline Toxic liquid in a $500 \mathrm{ml}$ bottle & Shelves & Occupational & High & Open & Planted \\
\hline Window ledges left unhygienic & Walls & Food & Medium & Open & Existing \\
\hline Bare wires & Walls & Occupational & High & Obscured & Planted \\
\hline Cigarettes on shelves & Shelves & Food & High & Open & Planted \\
\hline High level storage & Shelves & Occupational & Medium & Open & Planted \\
\hline Food not stored at the correct temperature & Shelves & Food & High & Open & Planted \\
\hline Overloaded sockets & Shelves & Occupational & Medium & Open & Planted \\
\hline Wedged fire door & Walls & Occupational & High & Open & Planted \\
\hline Moved fire extinguisher & Walls & Occupational & High & Open & Planted \\
\hline Floor damage & Floor & Food & Medium & Open & Existing \\
\hline Food on floor & Floor & Food & Medium & Open & Planted \\
\hline Floor left unhygienic & Floor & Food & Medium & Open & Existing \\
\hline Cross contamination in fridge or freezers & Storage & Food & High & Obscured & Planted \\
\hline
\end{tabular}

\footnotetext{
*The hazard was in direct line of sight.

**Inspectors had to manipulate their view in some way to observe the hazard, for example opening a fridge door, looking behind equipment, or going down on hands and knees to peer underneath equipment.
} 


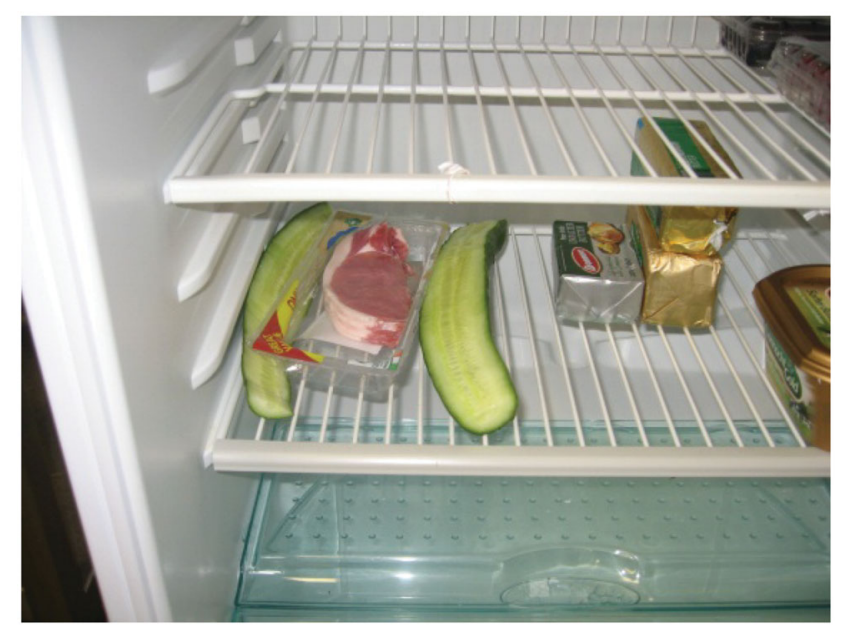

Figure 2. Cross contamination hazard in a fridge.

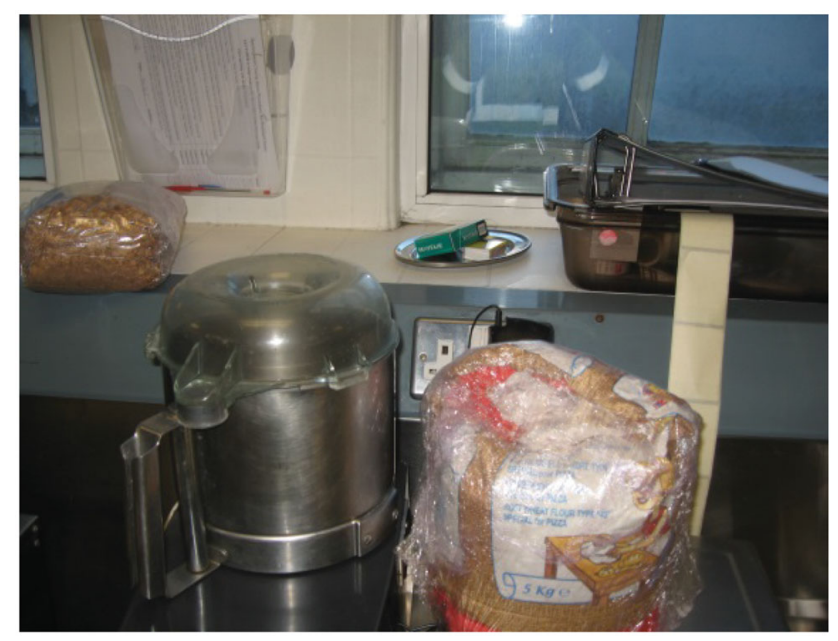

Figure 3. Cigarettes left on a shelf.

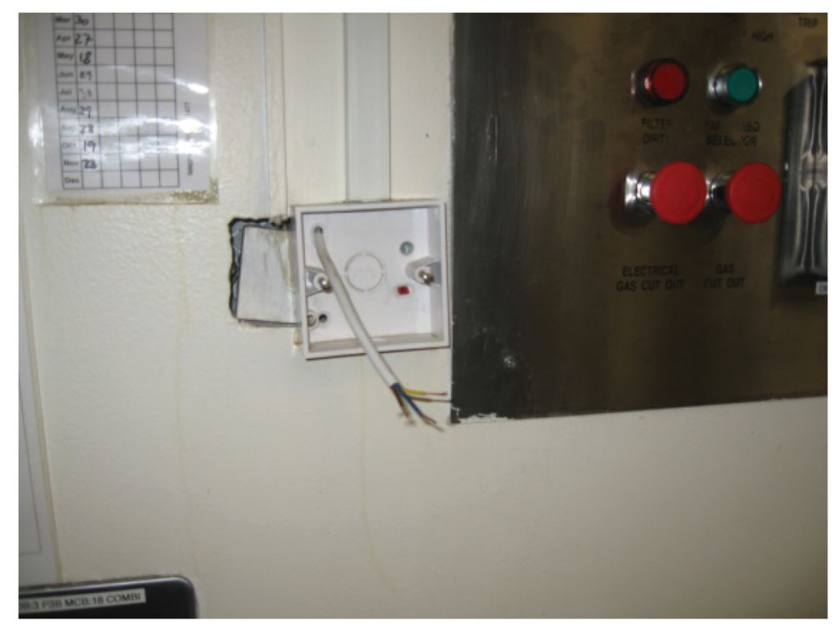

Figure 4. Bare wires. 


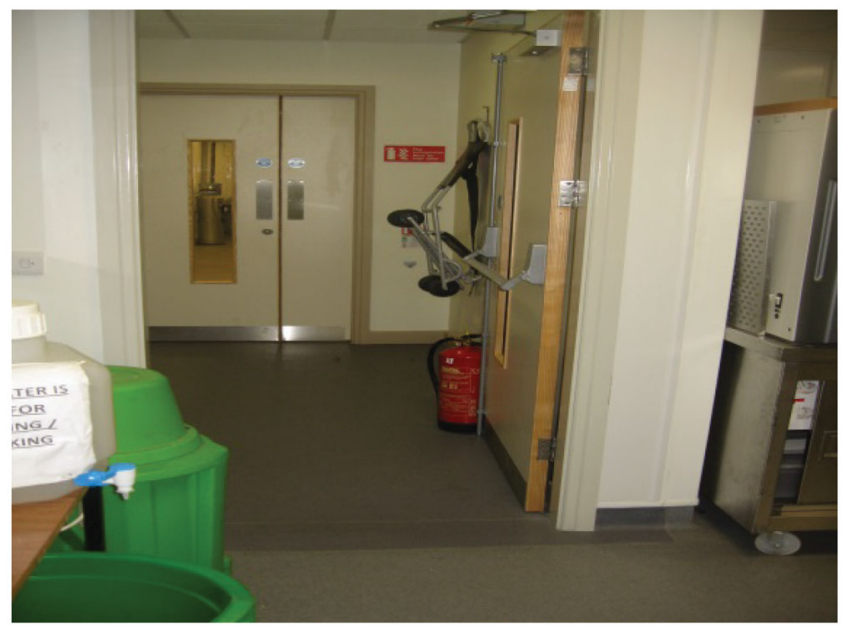

Figure 5. A fire door kept open by a fire extinguisher.

Table 4. Details on trial characteristics.

\begin{tabular}{|c|c|c|c|c|c|c|}
\hline Trial No. & Kitchen No. & Participant work status & Total $N$ & $N$ control & $N$ experimental & $N$ hazards present \\
\hline 1 & 3 & $\mathrm{FT}^{*}$ Students & 11 & $6(3,3)$ & $5(4,1)$ & 27 \\
\hline 2 & 3 & Professionals & 13 & $6(2,4)$ & $7(3,4)$ & 32 \\
\hline 3 & 2 & FT Students & 12 & $6(4,2)$ & $6(3,3)$ & 43 \\
\hline 4 & 1 & Professionals & 16 & $7(6,1)$ & $9(2,7)$ & 37 \\
\hline 5 & 1 & Professionals & 9 & $6(3,3)$ & $3(0,3)$ & 38 \\
\hline 6 & 5 & FT Students & 20 & $9(5,4)$ & $11(4,7)$ & 34 \\
\hline 7 & 1 & PT** Students & 19 & $9(2,7)$ & $10(5,5)$ & 40 \\
\hline 8 & 4 & PT Students & 19 & $11(4,7)$ & $8(3,5)$ & 36 \\
\hline 9 & 1 & PT Students & 11 & $6(5,1)$ & $5(4,1)$ & 35 \\
\hline 10 & 1 & PT Students & 22 & $11(4,7)$ & $11(4,7)$ & 38 \\
\hline 11 & 1 & FT Students & 24 & $12(5,7)$ & $12(4,8)$ & 38 \\
\hline 12 & 4 & FT Students & 35 & $18(1,17)$ & $17(13,4)$ & 36 \\
\hline Totals & & & 211 & 107 & 104 & \\
\hline
\end{tabular}

$\mathrm{FT}^{*}=$ Full Time, $\mathrm{PT}^{* *}=$ Part Time (figures in brackets show male and female numbers).

location. The research team's visual inspections and plants were conducted one hour prior to the trials and the kitchens then locked to prevent any interference until the participants arrived. Having conducted the visual inspections and plants, the researchers consulted each other to confirm an agreed hazard listing. The distribution of hazards within kitchens were kept as uniform as possible. However, due to the real world conditions used, the number of hazards within kitchens did vary somewhat between trials. For example, routine cleaning and changing stock levels meant that hygiene conditions in the kitchens could vary. Even so, the number of pre-ascertained hazards per trial was kept largely stable between kitchens and trials $($ Mean $=36.17, \mathrm{SD}=4.04)$ (Table 4).

\subsection{Randomised controlled trial procedure}

The randomised controlled trials were run as follows. Participants in each trial were firstly assembled in a lecture theatre by the researchers. An introductory lecture on common food and safety hazards found in kitchens was then delivered lasting thirty minutes. This lecture used typical educational pedagogy of PowerPoint displayed photographs and hazard listings. In this way all the participants received a brief but similar recap on the type of hazards to be found in kitchens, and more importantly, covering the range of hazards in the kitchens used. 
After the lecture period, participants were randomly assigned into treatment groups. Control group participants were then escorted to the trial kitchen where they were required to conduct visual inspections. During this inspection, they were directed to write down all the food and safety hazards they could identify within thirty minutes. Control group participants used A4 paper to write down the hazards they observed. After the control group had left the lecture theatre to begin their inspection task, the lead investigator delivered the systematic visual search intervention training using a thirty minute period with the experimental group. After the systematic visual search method was explained and demonstrated, the experimental group was escorted to the same kitchen as the control group and participants required to conduct visual inspections. Experimental group participants used specifically designed sheets of paper supporting the use of systematic visual search. The researchers choreographed entry and exit to the kitchens to ensure that control and experimental group participants did not encounter each other during the inspections.

At the end of the inspections, all documents with the written hazards by both treatment groups were collated for subsequent analysis. Inspection periods for both treatment groups were carefully invigilated by the researchers to prevent any plagiarism. The trials were conducted between December 2014 and April 2015. For the statistical analysis, all results were amalgamated to ensure significance testing with a large sample size, and with a resulting statistical power level of .9 (using a methodology described by Faul, Erdfelder, Lang, \& Buchner, 2007). The data was analysed using Microsoft Excel and SPSS v21.

\subsection{The intervention: systematic visual search method and training}

A syllabus was developed to ensure all experimental group participants were; firstly instructed in the systematic visual search method and secondly, directed to use the method during their subsequent inspection. The aim of the systematic visual search method is to get the inspector to observe all areas of any selected search field using foveated vision, which is known to provide maximum visual acuity (Eckstein, 2011; Wade \& Swanston, 2013). The use of foveated vision occurs when target objects are fixated in the eye's central field of vision. Outside this area, peripheral vision is used to resolve images but acuity levels fall sharply (Eckstein, 2011; Wade \& Swanston, 2013). To ensure foveated vision is used during the visual inspection, an eye scan pattern using an imaginary visual overlay template to direct inspector eye movement was explained as follows;

The kitchen to be inspected was to be firstly broken down into its constituent constructional and facilities elements being the ceiling, walls, floor, storage units and finally equipment. Each of these elements was then to be selected in this order, for individual systematic visual search by participants. Taking a wall as an example, this element was required to be observed in the following manner. The first observation or fixation begins in the top left corner of the selected wall. From there, the eyes move to the right, across the wall until right hand side of the wall is reached. The observation then recommences again at the left hand side of the wall but below the area already observed.

An explanatory analogy would be if a large sheet of paper with writing covered the entire wall and the participants were asked to read every word. In this way participants would observe all areas of the wall in the same way a person reading a book will see all the words on a page. This left to right then moving down eye strategy, ensures that there are no areas of the wall are left unobserved. It also ensures that wall areas are not repeatedly observed. One experimental group participant described systematic visual search behaviour very well by saying 'it was like painting the room with your eyes' Two further important procedures for systematic visual were also instructed; participant positioning and dealing with areas that could not be observed.

In terms of positioning, participants were instructed at all times; to locate themselves as close as possible to the area being observed. This was to be done by walking to the element or facility under analysis. This constant repositioning of the inspector, was to ensure foveal resolution and thereby maximise visual acuity during eye fixations on the hazards observed. When participants came to areas that were not 
observable, for example behind or under equipment they were instructed to do all they could to improve their vision of the obfuscated area. This included bending down, round, or on top of the item obscuring direct vision. Where possible, items were to be manipulated in some way by; pushing, pulling, opening or prising away to improve the line of sight. In terms of inspecting the floor, participants were told to get down on their hands and knees to observe any floor areas covered by equipment. Where direct vision was not possible, participants were instructed to continue on with their visual inspection.

In addition to the verbal instruction, documentation designed to support the use of systematic visual search was supplied for use during the inspection. The documentation consisted of single sheets of A4 paper, each with the room element to be inspected clearly written. Participants were therefore supplied with a total of eight sheets of collated paper. The first sheet was titled Ceiling the second sheet was titled North Wall, the next was titled East Wall and so on. Participants were instructed to use the sheets in the order they were given to facilitate the systematic visual search method. All participants were instructed to write down all the hazards they had observed.

All participants were given thirty minutes to complete their visual inspection. This thirty minute time period chosen was a pragmatic decision, taken during the experimental design stage. During pilot trials for the study, it was found that a thirty minute period ensured the continued motivation of participants and was logistically capable of being accurately implemented by the researchers. Some commentators such as Drury and Watson (2002) as well as Gallwey (1998) have recommended thirty minutes as a standard inspection period, after which a break is recommended. However there is no scientific evidence for an optimum inspection period and the time chosen was largely pragmatic.

The primary aim of the experimental design was to ensure as realistic a visual inspection task as possible, reflective of real world conditions. A simplification of the inspection task, could have been undertaken to increase internal validity, but would have been at the expense of real world applicability. The kitchens used were typical workplaces that EHS professionals would be expected to competently inspect. Anything other than realism regarding the inspection task would have compromised the utility of the findings when being generalised to the wider EHS community. As Zwarenstein et al. (2008) and Gaglio, Phillips, Heurtin-Roberts, Sanchez, and Glasgow (2014) report, pragmatism in the conduct of randomised controlled trials is unavoidable when evaluating the efficacy of real world interventions. Furthermore there have been calls from visual search scholars to conduct more applied studies in order to improve the theory and application of real world visual inspection tasks (for example see; Nakayama \& Martini, 2011; Wolfe et al., 2015).

\subsection{Further experimental design considerations}

The experimental design utilised the randomised controlled trial method for a number of reasons. Firstly the strength of this method which has been described as the "Gold Standard" in research and the best available when investigating field based interventions (Aronson, 2012; Moher et al., 2012; Schulz, Altman, \& Moher, 2010). Secondly by randomly allocating participants to treatment groups, the method evenly distributes any potential participant bias. Example of such bias could include; age, experience, motivation, levels of attentiveness or any ideosyncratic behaviour during inspection tasks such as participants actually seeing hazards but for some reason not categorising them as such. In this way the study results can be attributed as far as possible to the intervention, namely the use of systematic visual search.

A prospective longitudinal experimental design, whereby participants are given the inspection task before and after training in systematic visual search was considered but was rejected for the following reasons. Setting up and conducting such a pre and post intervention study would have been logistically more difficult to achieve. To reach the required statistical power of 64 participants for this experimental design, a much larger kitchen would have been required which was not available. Additionally given the size of the research team at the time, invigilation of the inspection task would have been more difficult with such large numbers of participants. 


\section{Results}

Participants who used the systematic visual search method, observed a mean $16.68 \%$ more hazards than their control colleagues (independent $t$-test $=12.12 ; p \leq .001$ ). A Cohen's $d$ result of 1.84 also demonstrates the large effect size resulting from the use of systematic visual search. As Table 5 clearly demonstrates, systematic visual search led to higher visual inspection performance.

A graphical summary of the visual performance of both groups is shown in Figure 6. below with control group data shown in light shade and experimental group data in dark shade.

It was also demonstrated that when compared to their control group colleagues; systematic visual search users had statistically significant higher levels of visual search performance $(p \leq .05)$ across twelve of the fourteen hazard categories. Regression analysis also demonstrates the strong effect of systematic visual search on participant performance when observing hazards. In particular the $\mathrm{R}^{2}$ result in Table 6 , shows that $41 \%$ of the variation in observed hazards, was due to the use of systematic visual search.

Figure 6 also shows that the largest differences between experimental and control group in terms of visual performance occurred with; ceiling tiles removed, bare wires, smoke detectors covered, hazards that

Table 5. Mean percentage hazards observed by control and experimental groups.

\begin{tabular}{lccrrrr}
\hline & $N$ & Mean percentage hazards observed & SD & $95 \%$ Cl's & $p^{*}$ value & Cohen's $d$ \\
\hline Control & 107 & 32.96 & 9.02 & {$[31.24-34.70]$} & & \\
Experimental & 104 & 49.64 & 10.88 & {$[47.53-51.76]$} & $\leq .001$ & 1.84 \\
\hline
\end{tabular}

*Using an Independent $t$-test.

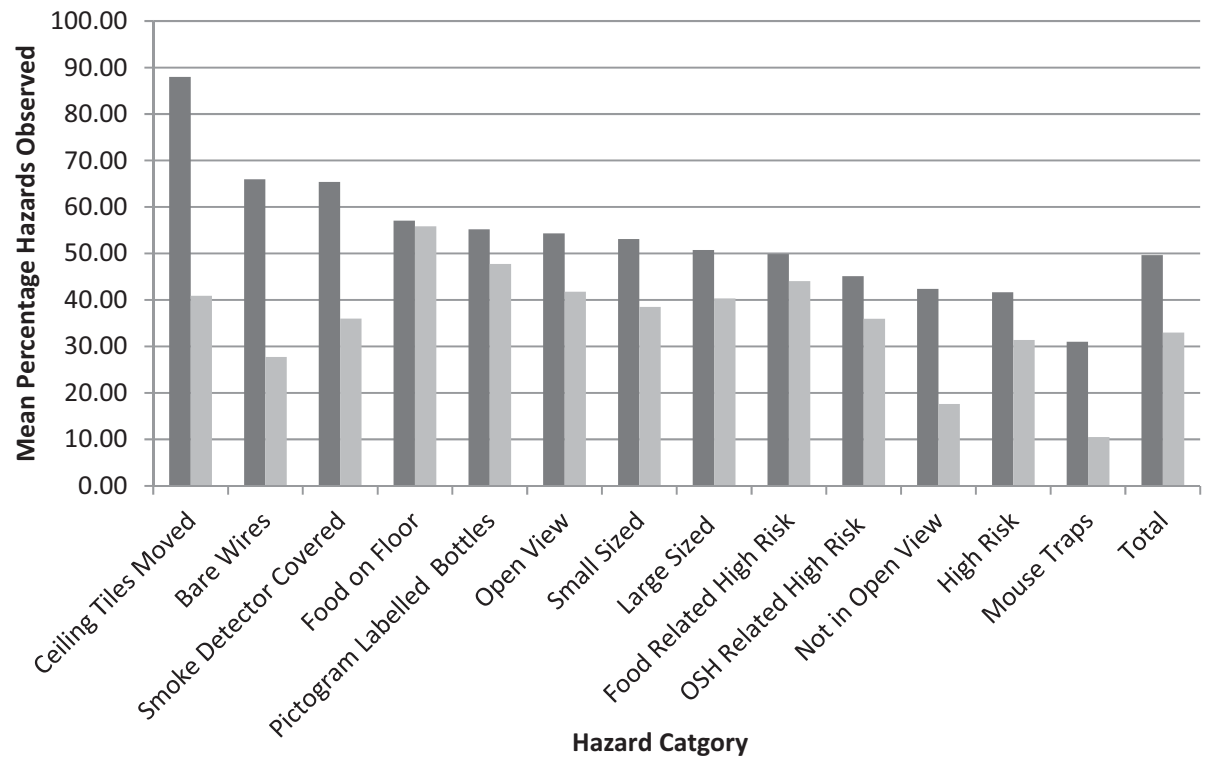

Figure 6. Comparison of hazards observed by control and experimental groups.

Table 6. Regression analysis results.

\begin{tabular}{lcccc}
\hline & $b_{0}$ & $\mathrm{SE} b_{0}$ & $b_{1}$ & $p$ \\
\hline Constant & 32.97 & 0.97 & $\leq .001$ \\
BCa 95\% confidence interval & {$[31.36-34.59]$} & & & \\
Participant treatment group & 16.67 & 1.41 & 0.64 & $\leq .001$ \\
BCa* 95\% confidence interval & {$[13.96-19.63]$} & & 0.41 \\
\hline
\end{tabular}

\footnotetext{
*Bias corrected and accelerated by SPSS v 21.
} 
Table 7. Mean number of hazards written down by control and experimental groups.

\begin{tabular}{lccccc}
\hline & Mean $N$ hazards written down & SD & $95 \%$ Cl's & $p^{*}$ value & Cohen's \\
\hline Control & 31.22 & 10.36 & {$[29.24-33.21]$} & & \\
Experimental & 48.86 & 12.92 & {$[46.34-51.37]$} & $\leq .001$ & 1.70 \\
\hline
\end{tabular}

*Using an Independent $t$-test.

were not in open view and mouse traps. The smallest and statistically non-significant differences in visual performance occurred with two hazard categories; food on the floor and pictogram labelled hazards. Therefore within the paradigm of this study, the utility of systematic visual search clearly lies with; the promotion of a consistent and exhaustive search behaviour, rather than any saliency characteristics of the hazards involved. In particular, inconspicuous and obfuscated hazards were far more likely to be observed with systematic visual search. Simply put, the increase in the number of hazards seen by the systematic visual search users was due to these inspectors being far more likely to; look up, behind, in, and underneath kitchen items and surfaces, in a manner reflective of the consistent and exhaustive dimension of this method.

A further interesting finding was that the number of hazards written down by experimental group participants when compared to their control group colleagues, which was a statistically significant $17.64 \%$ higher (Table 7).

This improvement in visual inspection performance is especially noteworthy when considering that systematic visual search users, will have had less inspection time available. This was because the experimental group participants wrote down a mean $17.64 \%$ more hazards than their control group colleagues. Consequently they will have spent more time writing and thereby less time observing when compared to control group participants.

To see if any experimental design bias was systematically affecting both treatment groups, the following five non-manipulated independent variables were statistically evaluated;

- Gender

- Experience, measured in years worked

- Work status either; full time student, part time student, or full time professional

- The number of hazards within kitchens, as well as by floor area and volume

- The kitchen inspected

Using Chi Square, correlation, ANOVA and multiple regression, relationships between the number of hazards observed by participants and these non-manipulated independent variables, were investigated. There were no significant results found. It is possible that the results could have been influenced by the participants being observed by the researchers. However, the results of this study were largely replicated in a separate aviation maintenance organisation (Hrymak, 2018). Here the same experimental design was applied but by the organisation's own employees and not the researchers in this study. Therefore, this source of bias does not seem to have had any statistically significant effect.

\section{Discussion}

The results clearly demonstrated that systematic visual search leads to superior in situ hazard observation performance within the paradigm used in this study. Furthermore no significant effects were detected from the experimental design so visual inspection accuracy was not predicted by gender, experience, the number of hazards present or the kitchen used. Together, these findings reinforce the conclusion that the main factor improving visual inspection performance in this study is; the use of a consistent and exhaustive visual search strategy as exemplified by the systematic visual search method. This study also clearly 
demonstrates that conducting visual inspections without using a consistent and exhaustive method is not easy, and will result in more observable hazards being missed.

The visual search literature also offers supporting evidence as to why systematic visual search would be advantageous. By using a set eye scanning pattern, a meticulous search of all areas under analysis is promoted (Nalangula et al., 2006; Nickles et al., 2003; Wang et al., 1997). Furthermore as search areas are not needlessly revisited, cognitive resources are conserved (Eckstein, 2011). The question now arises as to why, even with the use of systematic visual search, were the results disappointingly low from a professional practice point of view considering such a well trained cohort of participants. One contributory factor to the visual inspection performance of the systematic visual search users was that only thirty minutes of instruction was given prior to their inspection task. This is a very short time period in which to acquire a new skill and in itself, underscores the $16.68 \%$ improvement in visual inspection performance. Furthermore, the visual search literature (for example; See, 2012; Gallwey, 1998; Gramopadhye, Drury, \& Sharit, 1997) reports the positive effect of training and feedback. Therefore it is highly likely that visual inspection performance using systematic visual search will improve with additional training and feedback.

Another advantage of using the systematic visual search method, is its potential ability to reduce any cognitive bias that may be influencing the inspector. Kahneman (2011) makes an important point from an EHS professional practice perspective that experts need to continually check their decision making, in order to prevent cognitively biased intuition. The use of systematic visual search would greatly assist in ensuring that visual inspections are not influenced by any cognitive bias held by inspectors. It would do so by utilising a visual search behavioural algorithm that can counter the impact of cognitive bias by ensuring more hazards are actually observed.

However a downside of systematic visual search is that the method will increase the cost of inspections simply because they will take longer to conduct. Assuming a hypothetical one hour per $100 \mathrm{~m}^{2}$ (close to the mean size of kitchens used in this study), is made available to EHS professionals conducting workplace visual inspections. If this ratio is extrapolated to a hazard rich building such as a small food manufacturing facility of $1500 \mathrm{~m}^{2}$, it would entail circa $15 \mathrm{~h}$ of visual inspection time or nearly two days in terms of attendance. However it must be remembered that this increase in cost will also be accompanied by an increase in risk assessment accuracy, an improvement in legislative compliance and transparency regarding the professional conduct of the inspector.

It can also be argued that inspectors will identify non-observed in situ hazards during their inspections by using the remaining methods of hazard identification namely; asking questions, using checklists, reading on-site documents and scenario analysis. However it is intuitively difficult to see how any inspector who does not use a consistent and exhaustive visual search strategy, would be able to reliably identify any of the missed observable workplace hazards listed in Table 2. For example, would the attention of the inspector routinely be brought to covered smoke detectors, bare wires or cross contamination in fridges, simply by asking questions, using checklists, reading on-site documents or thinking about such occurrences?.

\subsection{The role of checklists during visual inspections}

The results of this study also prompts further debate on the role of checklists. As Clift et al. (2011) and Neathey et al. (2006) both demonstrate, the use of checklists is ubiquitous in the EHS community. These authors list their numerous advantages and disadvantages and some scholars such as Gawande (2009) regard checklists very highly. This author's best selling book; "The Checklist Manifesto" credits this method with many achievements, including successfully landing a damaged aircraft on the Hudson River, New York.

Nevertheless checklists remain a form of visual search and are subject to the same visual inspection errors listed in Table 1 above. There is scant literature on the empirical accuracy of checklists during workplace inspections but a small study was conducted whereby systematic visual search and checklists 
were compared on 11 industrial engineering sites (Curran \& Hrymak, 2019). In this study, the checklist approach elicited a small fraction of the observable hazards generated by systematic visual search.

This is not to downplay the importance of checklists as they have major advantages for visual inspection practice. As Clift et al. (2011) and Neathey et al. (2006) point out, checklists act as prompts and can add to inspector knowledge. Whilst the experimental design of this study did not involve the use of checklists, the results have prompted additional research which is currently being conducted by this study's authors. This includes assessing the empirical capability of checklists both as a stand alone hazard identification method and in combination with systematic visual search. Further strands to this inquiry include the effects of feedback on missed hazards, as well as repeatedly practicing visual inspection.

\section{Conclusions}

There are two main findings from this study. The first is that using a visual search behavioural algorithm such as systematic visual search, has demonstrated an improvement over current visual inspection practices. The second is that the base rates of visual inspection performance reported here, as well as in the literature, should be a matter of concern. Having shown in this study just how error prone hazard observation during visual inspections can be, it is important to further our knowledge of the cognitive processes involved in visual inspection. Reducing the non-observation of workplace hazards to an irreducible minimum can only benefit workplace safety.

Therefore introducing transparency, reliability and validity in the form of systematic visual search, will be a very worthwhile professional and academic initiative wherever visual inspection plays a key role. Finally competency criteria could also be better evidenced for EHS professionals, by involving a practical assessment of their visual inspection performance in the same manner as described in this study.

This work was supported by TU Dublin who funded the corresponding author's $\mathrm{PhD}$, from which this paper is derived.

\section{Disclosure statement}

No potential conflict of interest was reported by the authors.

\section{References}

Aimola-Davies, A.M., Waterman, S., White, C.R., \& Davies, M. (2013). When you fail to see what you were told to look for: Inattentional blindness and task instructions. Consciousness and Cognition, 22(1), 221-230. doi:10.1016/j.concog.2012.11. 015

Albert, A., Hallowell, M.R., \& Kleiner, B.M. (2014). Enhancing construction hazard recognition and communication with energy-based cognitive mnemonics and safety meeting maturity model: Multiple baseline study. Journal of Construction Engineering Management, 140, 1-11.

Aronson, E. (2012). The social animal (11th ed.). New York, NY: Worth Publishers.

Aven, T. (2011). Quantitative risk assessment, the scientific platform. Cambridge, UK: Cambridge University Press.

Baddeley, A.D. (2007). Working memory, thought and action. Oxford, UK: Oxford University Press.

Biggs, A.T., \& Mitroff, S.R. (2014). Different predictors of multiple-target search accuracy between non-professionals and professional visual searchers. Quarterly Journal of Experimental Psychology, 67(7), 1335-1348. doi:10.1080/17470218.2013. 859715

Cain, M.S., Adamo, S.H., \& Mitroff, S.R. (2013). A taxonomy of errors in multiple-target visual search. Visual Cognition, 21(7), 899-921. doi:10.1080/13506285.2013.843627

Carter, G., \& Smith, S.D. (2006). Safety hazard identification on construction projects. Journal of Construction Engineering and Management, 132(2), 197-205. doi:10.1061/(ASCE)0733-9364(2006)132:2(197)

Clark, K., Cain, M.S., Adcock, A.R., \& Mitroff, S.R. (2014). Context matters: The structure of task goals affects accuracy in multiple target visual search. Applied Ergonomics, 45(3), 528-533. doi:10.1016/j.apergo.2013.07.008

Clift, L., Lawton, C., \& Maguire, M. (2011). Checking the checklist: the effect of training on the application and effectiveness of checklist based risk assessments (Loughborough Design School. Report for the Institution of Occupational Safety and Health). Leicestershire (UK): Loughborough University Institutional Repository. 
Curran \& Hrymak. (2019). Which is the better method for hazard identification; checklists or training yourself to better observe workplace hazards? (Health and Safety Review, January/February 2019). Dublin, Ireland: IRN Publishing Limited.

Drew, T., Boettcher, S.E.P., \& Wolfe, J.M. (2015). Searching while loaded; Visual working memory does not interfere with hybrid search efficiency but hybrid search uses working memory capacity. Psychonomic Bulletin \& Review, 23, 201-212. doi:10.3758/s13423-015-0874-8

Drew, T., Vo, M.L.H., \& Wolfe, J.M. (2013). The invisible gorilla strikes again: Sustained inattentional blindness in expert observers. Psychological Science, 24(9), 1848-1853. doi:10.1177/0956797613479386

Drury, C.G., \& Watson, J. (2002). Good practices in visual inspection. Washington, DC: Federal Aviation Authority. US Department of Transportation. Retrieved from http://www.faa.gov/about/initiatives/maintenance_hf/library/?q= visual+inspection

Eckstein, M.P. (2011). Visual search: A retrospective. Journal of Vision, 11(5), 14-36. doi:10.1167/11.5.14

Faul, F., Erdfelder, E., Lang, A.G., \& Buchner, A. (2007). G*Power 3: A flexible statistical power analysis program for the social, behavioural and biomedical sciences. Behavior Research Methods, 39(2), 175-191. doi:10.3758/BF03193146

Fleck, M.S., Samei, E., \& Mitroff, S.R. (2010). Generalized "satisfaction of search": Adverse influences on dual-target search accuracy. Journal of Experimental Psychology: Applied, 16(1), 60-71. doi:10.1037/a0018629

Gaglio, B., Phillips, S.M., Heurtin-Roberts, S., Sanchez, M.A., \& Glasgow, R.E. (2014). How pragmatic is it? Lessons learned using PRECIS and RE-AIM for determining pragmatic characteristics of research. Implementation Science, 9(1), 96. doi:10. 1186/s13012-014-0096-x

Gallwey, T.J. (1998). Evaluation and control of industrial inspection. Part II. The scientific basis for the guide. International Journal of Industrial Ergonomics, 22(1-2), 51-65. doi:10.1016/S0169-8141(97)00067-X

Gawande, A. (2009). The checklist manifesto, how to get things right. London, UK: Profile Books.

Gilovich, T., Griffin, D.W.H., \& Kahneman, D. (2013). Heuristics and biases, the psychology of intuitive judgement. Cambridge, UK: Cambridge University Press.

Gould, J., Glossop, M., \& Ioannides, A. (2005). A review of hazard identification techniques (HSL/2005/58). Sheffield, UK: Health and Safety Laboratory, HMSO.

Gramopadhye, A.K., Drury, C.G., \& Sharit, J. (1997). Feedback strategies for visual search in airframe structural inspection. International Journal of Industrial Ergonomics, 19(5), 333-344. doi:10.1016/S0169-8141(96)00002-9

HSA. (2006). Guidelines on risk assessments \& safety statements. Dublin, Ireland: Health and Safety Authority of Ireland.

Hollis, M. (2000). Surveying buildings. Coventry, UK: Royal Institute of Chartered Surveyors Books. The Royal Institute of Chartered Surveyors.

Hollis, M., \& Bright, K. (1999). Surveying the surveyors. Structural Survey, 17(2), 65-75. doi:10.1108/02630809910273721

Hopkins, A. (2011). Management walk arounds: Lessons from the Gulf of Mexico oil well blowout. Safety Science, 49(10), 1421-1425. doi:10.1016/j.ssci.2011.06.002

Hrymak, V. (2018). The development and trial of systematic visual search; a novel training method designed to improve the observation of workplace hazards during visual inspections conducted for risk assessment and safety auditing purposes $(\mathrm{PhD}$ Thesis). University of Dublin at Trinity College. Retrieved from http://www.tara.tcd.ie/handle/2262/85144?show=full

Hrymak, V., DeVries, J.M.A., \& Leva, M.C. (2015). Workplace risk assessment in Ireland; is there a standard practice. Paper presented at Proceedings of the Irish Ergonomics Society Annual Conference. Trinity College Dublin, June, 2015.

HSE. (2014). Identify the hazards. Health and Safety Executive UK. Retrieved from http://www.hse.gov.uk/risk/identify-thehazards.htm

ISO 31010. (2009). Risk management - Risk assessment techniques. Geneva 20, Switzerland: International Standards Organisation.

Johansen, I.L., \& Rausand, M. (2015). Ambiguity in risk assessment. Safety Science, 80, 243-251. doi:10.1016/j.ssci.2015.07. 028

Kahneman, D. (2011). Thinking fast and slow. New York, US: Farrar, Strauss and Giroux Publishers.

Lenhardt, U., \& Beck, D. (2016). Prevalence and quality of workplace risk assessments - Findings from a representative company survey in Germany. Safety Science, 86, 48-56. doi:10.1016/j.ssci.2016.02.017

Lockhart, B.A. (2011). Inquiry into the deaths of 13 Residents of Rosepark Nursing Home Uddingston Scotland. Edinburgh, Scotland, UK: Sherrifdom of South Strathclyde Dumfries and Galloway.

Marhavilas, P.K., Koulouriotis, D., \& Gemeni, V. (2011). Risk analysis and assessment methodologies in the work sites: On a review, classification and comparative study of the scientific literature of the period; 2000-2009. Journal of Loss Prevention in the Process Industries, 24(5), 477-523. doi:10.1016/j.jlp.2011.03.004

Mariken, H.C., Everdij, H.A.P., \& Blom, A.P. (2013). Safety methods database, version 1.0 maintained by NLR. Netherlands Aerospace Centre. Retrieved from http://www.nlr-atsi.nl/services/safety-methods-database

Melloy, B.J., Harris, J.M., \& Gramopadhye, A.K. (2000). Predicting the accuracy of visual search performance in the structural inspection of aircraft. International Journal of Industrial Ergonomics, 26(2), 277-283. doi:10.1016/S01698141(99)00071-2

Mitroff, S.R., \& Biggs, A.T. (2014). The ultra-rare item effect: visual search for exceedingly rare items is highly susceptible to error. Psychological Science, 25(1), 284-289. doi:10.1177/0956797613504221 
Mitroff, S.R., Biggs, A.T., \& Cain, M.S. (2015). Multiple-target visual search errors: overview and implications for airport security. Policy Insights from the Behavioral and Brain Sciences, 2(1), 121-128. doi:10.1177/2372732215601111

Moher, D., Hopewell, S., Schulz, K.F., Montori, V., Gøtzsche, P.C., Devereaux, P.J., ... Altman, D.G. (2012). CONSORT 2010, explanation and elaboration: Updated guidelines for reporting parallel group randomised trials. BMJ, 2010(340), c869. doi:10.1136/bmj.c869

Montibeller, G., \& von Winterfeldt, D. (2015). Cognitive and motivational biases in decision and risk analysis. Risk Analysis, 35(7), 1230-1251. doi:10.1111/risa.12360

Moore, M., Brent, P.E., Phares, D., Graybeal, D., Rolande, D., \& Washer, G. (2001). Reliability of visual inspection for highway bridges. McLean VA: US Department of Transportation. Federal Highway Department. United States of America.

Nakayama, K., \& Martini, P. (2011). Situating visual search. Vision Research, 51(13), 1526-1537. doi:10.1016/j.visres.2010.09. 003

Nalangula, D., Greenstein, J.S., \& Gramopadhye, A.K. (2006). Evaluation of the effect of feedforward training displays of search strategy on visual search performance. International Journal of Industrial Ergonomics, 36, 289-300. doi:10.1016/j. ergon.2005.11.008

Neathey, F., Sinclair, A., Rick, J., Ballard, J., Hunt, W., \& Denvir, A. (2006). An evaluation of the five steps to risk assessment. Research Report 476. Health and Safety Executive UK.

Nickles, G.M., Melloy, B.J., \& Gramopadhye, A.K. (2003). A comparison of three levels of training designed to promote systematic search behaviour in visual inspection. International Journal of Industrial Ergonomics, 32(5), 331-339. doi:10.1016/ S0169-8141(03)00073-8

OSHA. (2016). OSHA inspections, occupational safety and health administration (OSHA Fact Sheet, DEP FS-3783 08/2016). US Department of Labor. Retrieved from https://www.osha.gov/OshDoc/data_General_Facts/factsheet-inspections.pdf

Perlman, A., Sacks, R., \& Barak, R. (2014). Hazard recognition and risk perception in construction. Safety Science, 64, 22-31. doi:10.1016/j.ssci.2013.11.019

Pinto, A., Ribeiro, R.A., \& Nunes, I.L. (2013). Ensuring the quality of occupational safety risk assessment. Risk Analysis, 33(3), 409-419. doi:10.1111/j.1539-6924.2012.01898.x

Rao, P., Bowling, S.R., Khasawneh, M.T., Gramopadhye, A.K., \& Melloy, B.J. (2006). Impact of training standard complexity on inspection performance. Human Factors and Ergonomics of Industrial Ergonomics, 20, 101-108.

RICS. (2002). Stock condition surveys (Guidance Note. Royal Institute of Chartered Surveyors). UK: The Royal Institute of Chartered Surveyors.

RICS. (2010). Building surveys and technical due diligence of commercial property (4th ed., Guidance Note GN23/2010. The Royal Institute of Chartered Surveyors). UK: The Royal Institute of Chartered Surveyors Practice Standards.

Schulz, K.F., Altman, D.G., \& Moher, D. (2010). CONSORT 2010 Statement: updated guidelines for reporting parallel group randomised trials. BMC Medicine, 8(1), 18. doi:10.1186/1741-7015-8-18

See, J.E. (2012). Visual Inspection: A Review of the Literature. Prepared by Sandia National Laboratories Albuquerque, New Mexico 87185 for the U.S. Department of Energy's National Nuclear Security Administration under contract DE-AC0494AL85000. 2012.

US Governmental Audit Office. (2004). Nursing home fire safety: Recent fires highlight weaknesses in federal standards and oversight. Report to Congressional Requesters, United States Government Accountability Office GAO-04-660. Retrieved from http://www.gao.gov/products/GAO-04-660

Wade, N.J., \& Swanston, M.T. (2013). Visual perception; an introduction. New York, NY: Psychology Press.

Wang, J.J.M., Lin, S.C., \& Drury, C.G. (1997). Training for strategy in visual search. International Journal of Industrial Ergonomics, 20(2), 101-108. doi:10.1016/S0169-8141(96)00043-1

Wolfe, J.M., Aizenman, A.M., Boettcher, S.E.P., \& Cain, M.S. (2016). Hybrid foraging search; Searching for multiple instances of multiple types of target. Vision Research, 119, 50-59. doi:10.1016/j.visres.2015.12.006

Wolfe, J.M., Evans, K.K., Drew, T., Aizenman, A., \& Josephs, E. (2015). How do radiologists use the human search engine? Radiation Protection Dosimetry, 169(1-4), 24-31. doi:10.1093/rpd/ncv501

Wolfe, J.M., Horowitz, T.S., \& Kenner, N.M. (2005). Rare targets are often missed in visual searches. Nature, 435(7041), 439-440. doi:10.1038/435439a

Woodcock, K. (2014). Model of safety inspection. Safety Science, 62, 145-156. doi:10.1016/j.ssci.2013.08.021

Zwarenstein, M., Treweek, S., Gagnier, J.J., Altman, D.G., Tunis, S., \& Moher, D. (2008). Research methods \& reporting. Improving the reporting of pragmatic trials: an extension of the CONSORT statement. BMJ, 337, a2390. doi:10.1136/bmj. a2390 